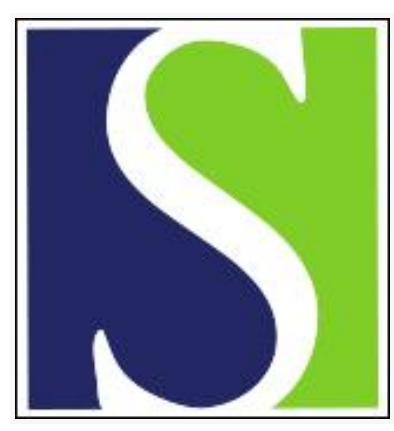

Scand J Work Environ Health 1995;21(2):116-123

https://doi.org/10.5271/sjweh.18

Issue date: Apr 1995

\title{
Cancer incidence among pharmaceutical workers
}

by Edling C, Friis L, Mikoczy Z, Hagmar L, Lindfors $P$

Key terms: acute leukemia; cancer of the lip; cancer of the peritoneum; cohort; epidemiology; renal pelvis; urinary bladder; urothelial cancer

This article in PubMed: www.ncbi.nlm.nih.gov/pubmed/7618057

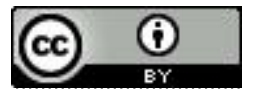




\title{
Cancer incidence among pharmaceutical workers
}

\author{
by Christer Edling, PhD, ${ }^{1}$ Lennart Friis, MD, ${ }^{1}$ Zoli Mikoczy, BSc, ${ }^{2}$ Lars Hagmar, PhD, ${ }^{2}$ Per Lindfors, $M D^{3}$
}

\author{
Edling C, Friis L, Mikoczy Z, Hagmar L, Lindfors P. Cancer incidence among pharmaceutical workers. Scand J \\ Work Environ Health 1995;21:116-23.
}

\begin{abstract}
Objectives A cluster of cancers at one plant in a pharmaceutical company in Sweden was the initiator for this work, which describes the cancer incidence among the laboratory and production workers at this company.

Methods The investigation is a retrospective cohort study. All employees with possible exposure to chemical, pharmacological, or biological agents and employment for at least six months at the company during 19601990 were included. Standardized incidence ratios (SIR) were calculated with the local county population as reference.

Results The total cancer incidence was close to the expected. In a subcohort consisting of the highest exposed employees, an SIR of 3.5 [95\% confidence interval (95\% CI) 1.5-6.8] was found for urothelial tumors, while there were no urothelial tumors among the workers with the lowest exposure. An evaluation of the exposures among the subjects with urothelial tumors revealed no association with specific exposures in the workplaces. There was also a statistically significant increase in the risk for acute leukemia (SIR 4.5, 95\% CI 1.2-12). With a 10-year induction-latency period in the calculations, the elevated risk was smaller and not significant. Although the numbers were small, there were also statistically significant overrisks for cancer of the peritoneum, the lip, and the pleura.

Conclusions A significant increase in the risk for urothelial tumors was found among pharmaceutical workers. All but one of those with urothelial tumors were smokers, but confounding from smoking could probably not explain the risk increase.
\end{abstract}

Key terms acute leukemia, cancer of the lip, cancer of the peritoneum, cohort, epidemiology, renal pelvis, urinary bladder, urothelial cancer.

Acute toxicity and other acute hazards of chemicals used in laboratories are well known, as well as the means and practices for their safe storage, handling and manipulation, chemical detoxification, and disposal. Less known or understood are the long-term hazards, such as genotoxicity, teratogenicity, and carcinogenicity. Health risks such as reproductive problems, chromosome abnormalities, and cancer have been reported for laboratory workers in many studies. An increased risk of cancer among workers in chemical laboratories has been reported from several countries. In an early study, Li et al (1) reported an excess of pancreatic and lymphohematopoietic neoplasm among members of the American Chemical Society, and Wynder \& Goldsmith (2) reported an increased risk of bladder cancer among pharmacists with previous exposure to chemicals. An increased risk of bladder cancer has also been reported for chemists (3). Olin \& Ahlbom $(4,5)$ described mortality patterns among Swedish chemists. Despite low overall mortality, an excess of brain cancer and lymphohematopoietic malignancies was found. A higher than expected incidence of brain tumors has also been reported at the Pasteur Institute in Paris (6) and for laboratory workers in England and Wales (7).

On the other hand, low cancer mortality was reported by Hoar \& Pell ( 8 ) in their study of chemists and chemical engineers employed by Dupont and by Maher \& Defonso (9) on chemical research workers.

Recently Belli et al (10) published their results from an epidemiologic study among employees at the Italian National Institute of Health. That study indicated elevated standardized mortality ratios for cancer of the pancreas and the brain, lympho- and reticulosarcomas, and lymphatic and hematopoietic tumors.

In 1989 the Occupational Health Unit at the pharmaceutical company Pharmacia AB, Uppsala, Sweden, notified that six cancer cases had occurred in 1986-1989.

1 Department of Occupational and Environmental Medicine, University Hospital, Uppsala, Sweden.

2 Department of Occupational and Environmental Medicine, University Hospital, Lund, Sweden.

3 Pharmacia Occupational Health Unit, Uppsala, Sweden.

Reprint requests to: Dr Christer Edling, Department of Occupational and Environmental Medicine, University Hospital, S-751 85 Uppsala, Sweden. 
The cases had appeared in a group of 120 employees. The reported cases were three cancers of the pancreas, one tumor of the brain, one stomach cancer, and one lung cancer. In view of the possible cancer hazard for laboratory workers a preliminary analysis was undertaken. This analysis revealed an excess risk in that group of workers when compared with expected numbers based on the local cancer incidence. To elucidate this excess risk further, an epidemiologic study was initiated. The interest was focused on cancer incidence among workers exposed to chemicals.

\section{Subjects and methods}

A retrospective entry cohort base was established, comprising all subjects who had worked for at least six months at the Pharmacia Company any time during the period 1960-1990. The inclusion criterion was, besides employment, a possible exposure to chemical, pharmacological, or biological agents. Thus not only laboratory workers, but also production personnel were included. The information collected for each subject included name, gender, date of birth, main work tasks, laboratory building, and dates of start and end of employment. Requested data for each person in the cohort were reported on a specific protocol that was filled out by the company for those who had left; the data were gathered from employment lists and personal knowledge and from workers who still worked at the company. According to data laws in Sweden, people still working have to sign an informed consent form, and they can refuse to participate if they wish. Among the reported 3620 subjects were 87 whose personal identification code could not be retrieved, and 19 of those still employed refused to participate. Therefore the cohort consisted of 3514 persons, of which 1821 were men and 1693 were women. Vital status was determined as of 31 December 1989. Ten individuals were lost to follow-up and excluded from the following analysis, leaving 3504 persons (93\%). Of the remaining persons, $92(2.5 \%)$ had died and 59 (1.6\%) had emigrated. The follow-up period was from 1 January 1960 through 31 December 1989, as the registers used for reference data had been updated only up to 1989.

Information about vital status and present address was collected from SPAR, a register of the entire Swedish population. Mortality data was collected from the National Death Register of Statistics Sweden. The information on cancer incidence was collected from the Swedish Cancer Register at the National Board of Health and Welfare.

The information on work tasks was the base for the exposure classification. An exposure subgrouping was made by representatives from the company and the unions. Four different groups were created. Group I comprised subjects working at chemical laboratories or production units including high risk laboratories (ie, special and separate facilities for laboratory-scale safe handling of highly toxic chemicals) and workers exposed to ionizing radiation (mainly from ${ }_{1} \mathrm{H}^{3},{ }_{6} \mathrm{C}^{14},{ }_{16} \mathrm{~S}^{35},{ }_{43} \mathrm{Tc}^{99 \mathrm{~m}}$ and ${ }_{53} \mathrm{I}^{125}$ ). Group II included those who had worked at pharmaceutical laboratories and production units. Group III was made up of workers from biological laboratories, and group IV included those who could be indirectly exposed to chemicals and the like in, for example cleaning, washing, and storage jobs and administrative personnel working within the laboratory and production facilities. The exposure was considered low among people with indirect exposure and highest among those working in chemical laboratories and chemical production. Workers who had belonged to more than one exposure subgroup during employment were allocated to the group where they had spent the longest exposure time. In cases of doubt, the highest exposure group in question was chosen. The potential exposures in the chemical laboratories have been extremely varied. With exception for common organic solvents, there had been no long-term exposures to any specific chemical compound. Substances now classified as carcinogens according to the Swedish National Board of Occupational Safety and Health (4-aminodiphenyl, benzidine and beta-naphthylamine) had been used in the chemical and pharmaceutical laboratories. Today these substances are banned, but there are still substances in use with carcinogenic potential (ie, diethyl sulfate, dimethyl sulfate, and ethylene dibromide). These substances were used with permission from the Factory Inspectorate.

An analysis of the distribution of the subjects by year of employment showed that $57 \%$ of the cohort members had started their work before 1981 , but only $5.3 \%$ were employed before 1961. The longest employment was 46 years and the shortest was six months (according to the inclusion criteria). The total time of work at the company for the cohort was 22924 years. The distribution of men and women into the different exposure categories is shown in table 1 .

Table 1. Distribution of the subjects in the cohort as to gender and exposure category. $[1=$ chemical, radiological and high risk exposures, $\|$ = pharmaceutical exposures, $I I I=$ biological exposures, $I V=$ indirect exposures (administrative, cleaning, washing and storage jobs)].

\begin{tabular}{lrrrr}
\hline Gender & \multicolumn{5}{c}{ Exposure category } \\
\cline { 2 - 5 } & \multicolumn{1}{c}{ I } & II & III & IV \\
\hline Men & 1096 & 351 & 65 & 309 \\
Women & 896 & 498 & 90 & 209 \\
\hline
\end{tabular}

Scand J Work Environ Health 1995, vol 21, no 2 
The epidemiologic analyses were performed with the computer program EPILUND at the Department of Occupational and Environmental Medicine, University Hospital, Lund, Sweden. Expected mortality for the period 1960-1989 was calculated with the use of mortality rates specific for calendar year, cause, gender, and fiveyear age groups in the county where the plant was located. These rates were obtained from Statistics Sweden. Similarly, yearly incidence rates for cancer in the period 1960-1989 were obtained from the Swedish Cancer Register. Date of death, a second tumor diagnosis, emigration, or a person's 80th birthday were used as individual end points, whichever occurred first. Finally the program computed standardized incidence ratios and $95 \%$ confidence intervals $(95 \% \mathrm{CI}$ ) according to the Poisson distribution, or to the normal distribution when the expected values is greater than 15 .

\section{Results}

\section{Mortality}

Overall, the cohort experienced fewer deaths than expected from all causes combined (92 observed versus 131 expected), including nearly every major category (total cancer, ischemic heart disease, nonmalignant respiratory diseases, diseases of the digestive system, and external causes of deaths). No significant elevation of any cause of death was observed. There were two deaths due to tumors in the brain versus 1.6 expected [standardized mortality ratio (SMR) $1.2,95 \%$ CI $0.15-$ 4.5]. Five of the cohort members had died in lymphohematopoietic malignancies. There were four cases of leukemia versus 1.5 expected (SMR 2.6, 95\%CI $0.7-$ 6.7) and one lymphoma versus 1.4 expected (SMR 0.70, $95 \%$ CI $0.02-3.9$ ).

\section{Cancer morbidity}

The site-specific cancer incidence was analyzed. Table 2 shows the results of the analysis when the county incidence data were used as reference. There were only minor differences in the results when a comparison was made with the general Swedish population and the county population as references. Gender-specific risk estimates are presented in table 2 for the calculations without an induction-latency period.

Acute leukemia ( 4 cases versus 0.9 expected) had a significantly elevated incidence, while the incidence of cancers in the urothelial organs (8 cases versus 3.5 expected) was almost significant.

Altogether, there were 72 cases of all cancers combined compared with 74 expected. The significantly in- creased risk estimate for cancer of the peritoneum was based on a single case. No significant risk increase was seen for brain cancer. Of the initially reported three cases of pancreatic carcinoma, one was a cancer in the biliary passages and the other two were cancer of the pancreas. Therefore cancer of the pancreas had a lower than expected incidence. The incidence for female breast cancer, the site with the most cases, was close to expected. When an induction-latency period of 10 years from the start of exposure until contribution to the person-years of the observation matrix was taken into account, the person years decreased from 42783 to 17017 , but the risk for urothelial cancer remained unchanged (table 2). On the other hand, three of the four cases of acute leukemia were lost, and therefore the standardized incidence ratio was reduced. Besides the gender-specific cancers, there were no remarkable gender-related differences in the risk estimates.

When the three highest exposed groups (I-III) were combined, the total cancer incidence was close to the expected, no induction-latency time being taken into account (table 3). In the lowest exposed group (IV) there was a significantly decreased cancer morbidity. The risk estimate for urothelial cancer increased after the lowest exposed group was excluded. Taking a 10-year induction-latency period into account did not add to the risk estimate. In contrast, the risk for acute leukemia was not affected by exposure group. When the lowest exposed group (IV) was excluded, the standardized incidence ratio for breast cancer increased to 1.4 , still a nonsignificant excess.

A more-detailed evaluation was made for the subjects with tumors in the renal pelvis or extrarenal urinary tract. The diagnoses from the cancer register were confirmed through a check of the clinical histories and the pathologist's original statements in the hospital records. Two of the reported tumors occurred in one person. First, he had a tumor in the renal pelvis. Six years later he was found to have a cancer in situ in the bladder. Furthermore, we learned from the hospital records that yet another patient had cancer in the renal pelvis with a following diagnosis of bladder cancer four years later. A third patient had multiple tumors. He initially had cancer in the ureter and subsequently developed cancer in situ in the bladder. Information about life-style factors was obtained from interviews with surviving patients, relatives, or fellow workers. All but one of the patients had been tobacco smokers. The interviews revealed nothing in the medical history nor previous medication with connection to possible confounding (eg, phenacetin abuse). No common determinant regarding work periods at the company, specific department, or chemical exposure was found. Using these findings as a basis and taking the small numbers into account, we did not undertake a case-referent study within the cohort. 
Table 2. Cancer incidence in 1960-1989 among the pharmaceutical workers of this study. ( $0=$ observed number of cancers, $\mathrm{E}=$ expected number of cancers, $\mathrm{SIR}=$ standardized incidence ratio, $95 \% \mathrm{Cl}=95 \%$ confidence interval). The county population was used as reference, except for peritoneum (ICD-7 158) for which the calculations were based on the national rates due to lacking regional data.

\begin{tabular}{|c|c|c|c|c|c|c|c|c|c|c|c|c|c|c|c|c|}
\hline \multirow[t]{2}{*}{ Cancer site ${ }^{a}$} & \multicolumn{4}{|c|}{$\begin{array}{l}\text { Men } \\
\text { (no induction-latency; } \\
\text { person years: } 23770 \text { ) }\end{array}$} & \multicolumn{4}{|c|}{$\begin{array}{c}\text { Women } \\
\text { (no induction-latency; } \\
\text { person years: } 19 \text { 013) }\end{array}$} & \multicolumn{4}{|c|}{$\begin{array}{c}\text { Total } \\
\text { (no induction-latency; } \\
\text { person years: } 42783 \text { ) }\end{array}$} & \multicolumn{4}{|c|}{$\begin{array}{c}\text { Total } \\
\text { (10 years induction-latency; } \\
\text { person years: } 17 \text { 017) }\end{array}$} \\
\hline & 0 & $E$ & SIR & $95 \% \mathrm{Cl}$ & 0 & $E$ & SIR & $95 \% \mathrm{Cl}$ & 0 & $E$ & SIR & $95 \% \mathrm{Cl}$ & 0 & $E$ & SIR & $95 \% \mathrm{Cl}$ \\
\hline & 2 & 0.39 & 5.2 & $0.63-19$ & - & 0.02 & 0.00 & $0.00-150$ & 2 & 0.41 & 4.9 & 0.59 & 2 & 0.29 & 7.0 & $0.85-25$ \\
\hline & 1 & 2.60 & 0.38 & $0.01-$ & 1 & 0.96 & 1.0 & $03-2+3$ & 2 & 3.57 & 0.56 & & 2 & 2.56 & 0.78 & -2.8 \\
\hline Colon (153) & 2 & 2.36 & 0.85 & $0.10-3.1$ & - & 1.66 & 0.00 & $0.00-2.2$ & 2 & 4.01 & 0.50 & & 2 & 2.85 & 0.70 & $0.08-2.5$ \\
\hline & 1 & 0.95 & 1.0 & $0.03-5.8$ & - & 0.70 & 0.00 & $0.00-5.2$ & 1 & 1.66 & 0.60 & & 1 & 1.28 & 0.78 & $0.02-4.3$ \\
\hline „.creas (157) & 2 & 1.60 & 1.2 & $0.15-4.5$ & - & 0.71 & 0.00 & $0.00-5.2$ & 2 & 2.32 & 0.86 & -3.1 & 1 & 1.71 & 0.59 & $0.01-3.3$ \\
\hline Jeritone & 1 & 0.01 & & $2.0-450$ & - & 0.01 & 0.00 & $0.00-490$ & 1 & 0.02 & 50 & 1.3 & 1 & 0.01 & 70 & $1.8-390$ \\
\hline & 5 & 3.99 & 1.2 & $0.41-2.9$ & 1 & 0.95 & 1.0 & $0.03-5.9$ & 6 & 4.94 & 1.2 & $0.45-2.6$ & 3 & 3.63 & 0.83 & $0.17-2.4$ \\
\hline (2) & 1 & 0.19 & 5.2 & -29 & - & 0.03 & 0.00 & $0.00-130$ & 1 & 0.22 & 4.6 & -25 & 1 & 0.18 & 5.4 & -30 \\
\hline & - & 0.03 & 0.00 & $0.00-110$ & 11 & 10.1 & 1.1 & $0.54-2.0$ & 111 & 10.1 & 1.1 & -1.9 & 8 & 6.80 & 1.2 & -2.3 \\
\hline Cervix & & . & . & & 1 & 2.65 & 0.38 & $0.01-2.1$ & 1 & 2.65 & 0.38 & -2.1 & - & 1.34 & 0.00 & -2.7 \\
\hline Corp & & $\cdot$ & $\cdot$ & & 1 & 1.58 & 0.63 & $0.02-3.5$ & 1 & 1.58 & 0.63 & $0.02-3.5$ & 1 & 1.09 & 0.92 & $0.02-5.1$ \\
\hline Ovar & : & . & . & & 2 & 1.99 & 1.0 & $0.12-3.6$ & 2 & 1.99 & 1.0 & -3.6 & - & 1.11 & 0.00 & $0.00-3.3$ \\
\hline & 3 & 6.83 & 0.44 & $0.09-1.3$ & . & , & . & $\cdot$ & 3 & 6.83 & 0.44 & -1.3 & 2 & 5.65 & 0.35 & -13 \\
\hline & 3 & 1.72 & 1.7 & $0.36-5.1$ & & . & . & & 3 & 1.72 & 1.7 & $0.36-5.1$ & 1 & 0.61 & 1.6 & $0.04-9.1$ \\
\hline & 0 & 1.52 & 0.00 & $0.00-2.4$ & 1 & 0.56 & 1.8 & $05-10$ & 1 & 2.08 & 0.48 & & 1 & 1.40 & 0.71 & $0.02-4.0$ \\
\hline & 7 & 2.96 & 2.4 & $0.95-4.9$ & 1 & 0.59 & 1.7 & $0.04-9.4$ & 8 & 3.54 & 2.3 & $0.98-4.4$ & 6 & 2.61 & 2.3 & $.84-5.0$ \\
\hline Renal pe & 2 & 0.17 & 12 & $1-43$ & - & 0.05 & 0.00 & $0.00-79$ & 2 & 0.21 & 9.3 & $1.1-34$ & 1 & 0.16 & 6.4 & $0.16-36$ \\
\hline & 5 & 2.79 & 1.8 & $8-4.2$ & 1 & 0.54 & 1.9 & $0.05-10$ & 6 & 3.33 & 1.8 & $0.66-3.9$ & 5 & 2.45 & 2.0 & $0.66-4.8$ \\
\hline & 1 & 1.65 & 0.60 & $0.02-3.4$ & 一 & 1.49 & 0.00 & $000-25$ & 1 & 3.14 & 0.32 & & - & 1.91 & 0.00 & $0.00-1.9$ \\
\hline Nervol & 3 & 2.23 & 1.4 & $0.28-3.9$ & 2 & 1.72 & 1. & $0.14-4.2$ & 5 & 3.95 & 1.3 & $0.41-3.0$ & 1 & 2.14 & 0.47 & $0.01-2.6$ \\
\hline Thyroid & - & 0.37 & 0.00 & $0.00-10$ & 2 & 0.94 & 2.1 & $0.26-7.7$ & 2 & 1.31 & 1.5 & $0.18-5.5$ & 1 & 0.74 & 1.4 & $0.03-7.6$ \\
\hline Endocrine glands (195) & 1 & 0.79 & 1.3 & $0.03-7.0$ & 3 & 1.14 & 2.6 & $0.54-7.7$ & 4 & 1.93 & 2.1 & $0.56-5.3$ & 2 & 1.25 & 1.6 & $0.19-5.8$ \\
\hline & 1 & 1.45 & 0.69 & & 1 & 0.71 & 1.4 & $4-7.8$ & 2 & 2.17 & 0.92 & & 1 & 1.44 & 0.69 & $0.02-3.9$ \\
\hline Hodgkin's disease (201) & 2 & 0.68 & 2.9 & $0.36-11$ & - & 0.33 & 0.00 & $.00-11$ & 2 & 1.01 & 2.0 & $0.24-7.2$ & 1 & 0.37 & 2.7 & $0.07-15$ \\
\hline Multiple myeloma (203) & 0 & 0.59 & 0.00 & $0.00-6.3$ & 1 & 0.25 & 4.0 & $0.10-22$ & 1 & 0.84 & 1.2 & $0.03-6.6$ & 1 & 0.65 & 1.6 & $0.04-8.6$ \\
\hline mia & 3 & 0.54 & 5.6 & & 1 & 0.34 & 2.9 & & 4 & 0.88 & 4.5 & & 1 & 0.50 & 2.0 & $0.05-11$ \\
\hline & 43 & 41.3 & 1.0 & $0.76-1.4$ & 29 & 33.2 & 0.87 & $0.59-1.3$ & 727 & & 0.97 & $0.76-1.2$ & & 00.1 & 0.88 & $0.64-1.2$ \\
\hline
\end{tabular}

a Codes of the International Classification of Diseases (seventh revision) in parentheses.

\section{Discussion}

This study showed a significantly increased risk for cancer in organs with urothelium (ie, renal pelvis and extrarenal urinary tract combined) among subjects working at a pharmaceutical company. However, further analysis could not reveal any specific chemical exposure as the cause of this increased risk. Acute leukemia had a significantly increased risk when no latency was applied in the analysis, but no significant increase with 10 years' latency. On the basis of small numbers there were also significant increases in cancers of the peritoneum and lip.
We found no significantly increased morbidity for all malignant tumors combined, nor for malignancies in the brain or pancreas.

The validity aspects of the study deserve some comments. The employment lists were complete and also allowed us to include those who had left the company. Regarding selection bias, the subjects included in the study were everyone from the study base who fulfilled the inclusion criteria, except 19 who refused to participate and 87 for whom we were unable to find the correct personal identification codes. These losses are not expected to have led to any differential misclassification. 
Table 3. Cancer incidence in 1960-1989 among the pharmaceutical workers in the three highest exposure categories (I, II, III) and lowest (IV) category. ( $O$ = observed number of cancers, $E=$ expected number of cancers, $S I R=$ standardized incidence ratio, $95 \% \mathrm{Cl}=95 \%$ confidence interval). The county population was used as reference, except for peritoneum (ICD-7 158) for which the calculations were based on the national rates due to lacking regional data.

\begin{tabular}{|c|c|c|c|c|c|c|c|c|c|c|c|c|c|c|c|c|}
\hline \multirow[t]{2}{*}{ Cancer site } & \multicolumn{4}{|c|}{$\begin{array}{l}\text { Exposure groups I, II, III } \\
\text { (no induction-latency; } \\
\text { person years: } 36 \text { 397) }\end{array}$} & \multicolumn{4}{|c|}{$\begin{array}{l}\text { Exposure group IV } \\
\text { (no induction-latency; } \\
\text { person years: } 6128 \text { ) }\end{array}$} & \multicolumn{4}{|c|}{$\begin{array}{l}\text { Exposure groups I, II, III } \\
\text { (10 years induction-latency; } \\
\text { person years: 14 472) }\end{array}$} & \multicolumn{4}{|c|}{$\begin{array}{c}\text { Exposure group IV } \\
\text { (10 years induction-latency; } \\
\text { person years: } 2453 \text { ) }\end{array}$} \\
\hline & 0 & E & SIR & $95 \% \mathrm{Cl}$ & 0 & E & SIR & $95 \% \mathrm{Cl}$ & 0 & E & SIR & $95 \% \mathrm{Cl}$ & 0 & E & SIR & $95 \% \mathrm{Cl}$ \\
\hline Lip (140) & 2 & 0.27 & 7.5 & $0.90-27$ & - & 0.14 & 0.00 & $0.00-26$ & 2 & 0.20 & 9.8 & $1.2-35$ & - & 0.08 & 0.00 & $0.00-45$ \\
\hline Stomach (151) & 2 & 2.30 & 0.87 & $0.11-3.1$ & - & 1.24 & 0.00 & $0.00-3.0$ & 2 & 1.76 & 1.1 & $0.14-4.1$ & - & 0.79 & 0.00 & $0.00-4.7$ \\
\hline Colon (153) & 2 & 2.58 & 0.78 & $0.09-2.8$ & - & 1.42 & 0.00 & $0.00-2.6$ & 2 & 1.86 & 1.1 & $0.13-3.9$ & - & 0.98 & 0.00 & $.00-3.8$ \\
\hline & 1 & 1.04 & 0.96 & $0.02-5.4$ & - & 0.61 & 0.00 & $0.00-6.0$ & 1 & 0.83 & 1.2 & $0.03-6.7$ & - & 0.45 & 0.00 & $0.00-8.2$ \\
\hline Pancr & 2 & 1.43 & 1.4 & $0.17-5.1$ & - & 0.90 & 0.00 & $0.00-4.2$ & 1 & 1.12 & 0.89 & $0.02-5.0$ & - & 0.58 & 0.00 & $0.00-6.3$ \\
\hline Peritone & 1 & 0.01 & & $1.9-430$ & - & 0.01 & 0.00 & $0.00-530$ & 1 & 0.011 & 00 & 2. $6-580$ & - & 0.00 & 0.00 & $0.00-770$ \\
\hline & 3 & 3.19 & 0.94 & $0.19-2.8$ & 3 & 1.72 & 1.7 & $0.36-5.1$ & 2 & 2.52 & 0.79 & & 1 & 1.11 & 0.90 & -5.0 \\
\hline Pleu & - & 0.15 & 0.00 & 0.00 & 1 & 0.07 & 14 & $0.36-78$ & - & 0.13 & 0.00 & & 1 & 0.05 & 19 & -100 \\
\hline Breas & 10 & 7.22 & 1.4 & $0.66-2.6$ & 1 & 2.92 & 0.34 & $0.01-1.9$ & 7 & 5.02 & 1.4 & $0.56-2.9$ & 1 & 1.77 & 0.57 & $0.01-3.2$ \\
\hline Cervix & - & 2.12 & 0.00 & $0.00-1.7$ & 1 & 0.53 & 1.9 & $0.05-11$ & - & 1.12 & 0.00 & $0.00-3.3$ & - & 0.22 & 0.00 & $0.00-17$ \\
\hline corp & 1 & 0.91 & 1.1 & 6.1 & - & 0.67 & 0.00 & $0.00-5.5$ & 1 & 0.68 & 1.5 & $0.04-8.1$ & - & 0.40 & 0.00 & $0.00-9.2$ \\
\hline Ovary & 1 & 1.36 & 0.73 & $0.02-4.1$ & 1 & 0.62 & 1.6 & $0.04-9.0$ & - & 0.78 & 0.00 & $0.00-4.8$ & - & 0.33 & 0.00 & -11 \\
\hline Prost & 1 & 4.05 & 0.25 & $0.01-1.4$ & 2 & 2.74 & 0.73 & $0.09-2.6$ & - & 3.64 & 0.00 & $0.00-1.0$ & 2 & 2.00 & 1.0 & $0.12-3.6$ \\
\hline |est| & 2 & 1.49 & 1.3 & & 1 & 0.23 & 4.4 & $0.11-2$ & 1 & 0.54 & 1.9 & 0.0 & - & 0.07 & 0.00 & $00-52$ \\
\hline & 1 & 1.37 & 0.73 & $0.02-4.1$ & - & 0.70 & 0.00 & $0.00-5.3$ & 1 & 0.99 & 1.0 & $0.03-5.6$ & - & 0.41 & 0.00 & $0.00-8.9$ \\
\hline & 8 & 2.31 & 3.5 & & - & 1.21 & & & 6 & 1.80 & & & - & 0,79 & 0.00 & $.00-4.7$ \\
\hline Renal pelvis (180.1) & 2 & 0.13 & 16 & $1.9-57$ & - & 0.08 & 0.00 & $0.00-44$ & 1 & 0.10 & 9.6 & $0.24-54$ & - & 0.05 & 0.00 & $0.00-70$ \\
\hline & 6 & 2.18 & 2.8 & $1.0-6.0$ & - & 1.13 & 0.00 & $0.00-3.3$ & 5 & 1.70 & 2.9 & & - & 0.74 & 0.00 & $0.00-5.0$ \\
\hline & 1 & 2.55 & 0.39 & $1-2.2$ & - & 0.58 & 0.00 & & - & 1.57 & 00 & & - & 0.33 & 0.00 & $00-11$ \\
\hline Nervou & 5 & 3.06 & 1.6 & $0.53-3.8$ & - & 0.87 & 0.00 & $0.00-4.2$ & 1 & 1.67 & 0.60 & $0.02-3$ & - & 0.46 & 0.00 & $0.00-8.0$ \\
\hline Thyro & 1 & 1.05 & 0.95 & $02-5.3$ & 1 & 0.26 & 3.9 & $0.10-22$ & - & 0.59 & 0.00 & $0.00-6.2$ & 1 & 0.14 & 7.1 & $0.18-40$ \\
\hline Endocrine glands (195) & 4 & 1.44 & 2.8 & $0.76-7.1$ & - & 0.49 & 0.00 & $0.00-7.6$ & 2 & 0.94 & 2.1 & $0.26-7.7$ & - & 0.31 & 0.00 & $0.00-12$ \\
\hline & 1 & 1.53 & 0.65 & $0.02-3.6$ & 1 & 0.62 & 1.6 & $0.04-8.9$ & 1 & 1.03 & 0.97 & $0.02-5.4$ & - & 0.41 & 0.00 & $0.00-9.1$ \\
\hline Hodgkin's & 2 & 0.82 & 2.4 & $0.30-8.8$ & - & 0.18 & 0.60 & $0.00-20$ & 1 & 0.30 & 3.4 & $0.08-19$ & - & 0.07 & 0.00 & $0.00-50$ \\
\hline Multiple myeloma (203) & - & 0.52 & 0.00 & $0.00-7.1$ & 1 & 0.32 & 3.1 & $0.08-18$ & - & 0.42 & 0.00 & $0.00-8.8$ & 1 & 0.23 & 4.4 & $0.11-25$ \\
\hline $\begin{array}{l}\text { Acute leuk } \\
(204.0+2\end{array}$ & 3 & 0.66 & 4.5 & $0.94-13$ & 1 & 0.21 & 4.6 & $0.12-26$ & 1 & 0.38 & 2.7 & $0.07-15$ & - & 0.12 & 0.00 & $0.00-30$ \\
\hline All sites $(140-209)$ & 585 & 51.2 & 1.1 & $0.87-1.5$ & 14 & 23.0 & 0.61 & $0.33-1.0$ & 373 & 35.4 & 1.0 & $0.74-1.4$ & & 14.6 & 0.48 & $0.19-0.9$ \\
\hline
\end{tabular}

a Codes of the International Classification of Diseases (seventh revision) in parentheses.

The follow-up was successful for more than $96 \%$ of the cohort members, and data completeness appears to have been satisfactory.

This study was carried out retrospectively, and we have no measurements of previous exposure in the various departments. Nevertheless, great care was taken to assign cohort members to the exposure groups correctly. This exposure classification was made in the same way for those who had left the company and those still employed. The individual occupational history was obtained from job records and validated by the heads of the company and the supervisors of participating departments, who had worked there for many years and knew most workers personally. Information bias might have occurred if these people were aware of the outcome for the included subjects. If so, the cases may have been surveyed more intensively than the noncases. However, we have no indication that this was the case in our study. Differential misclassification of exposure status was therefore expected to be minimal.

Information on cancer incidence was uniformly collected for all the cohort members, through the Swedish Cancer Register at the National Board of Health and Welfare. We had no particular reference group, but used 
the general Swedish and local populations as reference. The use of national rates in the analysis has the advantage of the stability of expected numbers. Such methods can validly be used to calculate standardized incidence ratios, as long as no strong regional fluctuations in cancer incidences exist. For this cohort we also used the regional population in separate analyses and thereby minimized the risk for misleading results due to possible regional fluctuations in cancer incidences.

The use of general populations as reference might be questioned since they include groups with morbidity patterns differing from workers with long-term employment. In cohorts of active workers the observed number of deaths therefore often falls short of expected numbers calculated from national averages, especially if no induction-latency requirement is applied. This phenomenon is usually referred to as the healthy worker effect, and it adds to the insensitivity of the cohort study.

In this study the follow-up was stopped at a second tumor diagnosis. When only mortality in cancer is possible to study, the problem of cut-off does not exist. However, when one studies cancer incidence, one must consider this carefully. A rationale for cutting the follow-up period off already after the first tumor diagnosis is that anticancer treatment (eg, with radiation or cytostatic agents) may increase the risk for a second tumor in subjects from the cohort under study. Thus person-years included after a tumor diagnosis might therefore carry incident cancer cases due to the anticancer treatment, besides those due to the exposure under study. This procedure will introduce some bias when a comparison is made with expected values calculated from the general population. On the other hand, cutting off already after the first tumor diagnosis decreases the precision of the study due to fewer incident cases, and it may also introduce some bias (multiple primaries). We do not think that there is a simple solution to this problem, and we have used a second tumor diagnosis as the cut-off as a reasonable compromise.

All five cases of brain cancer belonged to the highest exposed groups versus four expected. However, when an induction-latency period of 10 years was allowed for, there was only one case left versus two expected. Thus the inconsistently reported risk increase for brain cancer among laboratory workers was not supported by the present data.

The higher than expected risk for cancer of the lip among the highest exposed persons became significant and increased when a 10-year induction-latency period was introduced into the analysis. This finding is consistent with a relation with the work. However, there were only two cases, and we have not been able to identify any exposure at work explaining these two tumors. Tumors of the lip will be of interest in the future follow-up of this cohort.
The four cases of acute leukemias were not concentrated among workers categorized as having the most intense exposure to chemicals, pharmaceuticals, or biological material, nor were they concentrated among workers with long-term exposure in any of the areas. In fact, three of the patients had less than 10 years of latency from employment to diagnosis. The relatively small number of cases and the multiple exposures of the workers make it impossible to point to a particular agent as a likely cause of the excess, if indeed, any of the cases were related to the work environment. However, the findings agree with other data indicating an increased risk of lymphohematopoietic malignancies among laboratory workers $(1,4,10)$.

The slight increase in breast cancer morbidity among the women with the highest exposure might deserve a comment. Three earlier studies have found an increased risk for breast cancer among female chemists $(10,11$, 12). The major risk factors for breast cancer are medication with hormones, diet, and reproductive history. We had no information on these. Ionizing radiation, including low-level diagnostic radiation, is also a risk factor for breast cancer. Radioactive isotopes have been in use at the company, and additional information on the exposure history of the cases is necessary to elucidate a possible relationship between that exposure and breast cancer. Ten out of the 11 cases of breast cancer belonged to the three highest exposure groups - versus seven expected. Allowing for a latency period of 10 years did however not increase the risk estimates.

There was a significant excess of cancer from the renal pelvis and extrarenal urinary tract combined among the highly exposed subjects. This significant excess also remained when a 10 -year latency period was taken into account. Two of the eight reported urothelial tumors were in one patient, initially in the renal pelvis and six years later in the bladder. Hospital records revealed that two other patients had multifocal metachronous tumors of urothelial origin. This finding agrees with the common experience of this disease. There is an ongoing discussion on whether these multifocal and metachronous tumors in the transitional epithelium are the result of one monoclonal oncogen activation or if they develop independently of each other as a result of a multiclonal activation caused by, for example, chemical carcinogens acting on the tissue $(13,14)$. Multiple tumors in the bladder do not normally cause multiple registrations in the Swedish Cancer Register, unless there are specific differences in the histopathological staging. Tumors in the renal pelvis [code 180.1 of the seventh revision of the International Classification of Diseases (ICD-7)] and tumors in ureter or bladder (ICD-7 181) are coded separately in the cancer register and usually lead to separate registrations for one patient (personal communication from E Martin, Swedish Cancer Register). Thus one 
could expect that our subject with double registrations is not unique and that also the expected numbers are affected accordingly.

Risk factors for urothelial cancer are tobacco, diet, and certain chemical exposures. Rehn discussed aniline exposure as a possible cause of cancer of the urinary bladder as early as 1895. Later it has been suggested that the aromatic amines beta-naphthylamine, 4-aminodiphenyl, and benzidine were the causative agents for the earlier-reported increased incidence of bladder cancer among workers. Other studies $(2,3)$ have also reported an increased risk of bladder cancer (although not statistically significant) among chemists and pharmacists with chemical exposure. In these studies no specific substance has been suggested as the causative agent. The observed excess in our study might be due to exposures at the workplace, but a closer examination of the seven individuals with urothelial cancer revealed no common exposure. The analgesic phenacetin is a known risk factor for tumors in the transitional epithelium. Nothing in the hospital records indicated any chronic pain problem in any of these persons. Neither was there anything in the evaluation that pointed to a misuse of phenacetin analgesics among these persons. Smoking is a cause of urothelial cancer. The evaluation of the life-style factors, based on hospital records and interviews with the cases, relatives or fellow-workers, showed that all but one of the seven cases had been smokers. However, there was no data on the smoking habits in the whole cohort, either today or two to three decades ago. A recent survey among 500 employees in one part of the company showed that 58 (about $12 \%$ ) smoked. This is a low figure with probably little relevance to the situation 20 to 30 years ago. It can be assumed that, as in the rest of the Swedish population, the number of smokers has decreased among the employees at the company during the last few decades, and, according to a personal communication (K-E Doversten, Kabi Pharmacia Diagnostics) probably $50 \%$ or more of the employees were smokers in the 1950s and early 1960s. The observed excess in urothelial cancers is of the same magnitude as the increased risk for bladder cancer among smokers compared with nonsmokers (15). On the basis of these figures the role of confounding from smoking can be calculated (16). If $50 \%$ of the exposed subjects and $60 \%$ of the reference population were smokers, a risk ratio of 0.9 could be explained by a difference in smoking habits. If $100 \%$ of the cohort members were smokers and $30 \%$ of the referents, the risk ratio would be 1.9. From the risk estimates for lung cancer, it can be assumed that the smoking rate was about the same for the Pharmacia workers as for the general population. Smoking alone is therefore not a sufficient explanation for the risk increase in the cohort. One possible explanation is effect modification by tobacco smoking or some occupational exposure that we were unable to identify.
Another possibility is the statistical uncertainty in our risk estimates.

Since there is usually a delay between exposure to a carcinogen and the development of cancer, the present results would largely reflect the effects of past exposure in the laboratories. The type of work done by individuals in each occupational group was diverse and cannot therefore exclude the possibility that some specific but infrequent exposure might be associated with an increased cancer risk. Our data suggest that past exposure has not resulted in an unusual pattern of cancer in this pharmaceutical industry cohort as a whole, apart from an excess of cancers in organs with urothelium.

In light of our observations, a major cancer risk among employees at the Pharmacia Pharmaceutical Company can be ruled out. The numerical excess of acute leukemia and brain tumors appears to be consistent with observations from other occupational investigations. The finding of an excess of cancer of the renal pelvis and extrarenal urinary tract could not be related to any specific chemical exposure. This cohort will be followed in the future.

\section{Acknowledgments}

We acknowledge the help of Susanne Siewertz and her colleagues at Pharmacia $\mathrm{AB}$ for their work in tracing the cohort members and classifying their exposures.

\section{References}

1. Li FP, Fraumeni JF, Mantel N. Cancer mortality among chemists. JNCI 1969;43:1159-64.

2. Wynder EL, Goldsmith R. The epidemiology of bladder cancer. Cancer 1977;40:1246-68.

3. Claude JC, Frentzel-Beyme RR, Kunze E. Occupation and risk of cancer of the lower urinary tract among men: a casecontrol study. Int J Cancer 1988;41:371—9.

4. Olin GR, Ahlbom A. The cancer mortality among chemists. JNCI 1969;43:1159-64.

5. Olin GR, Ahlbom A. The cancer mortality among Swedish chemists graduated during three decades. Environ Res 1980;22:154 61.

6. Cordier S. Risk of cancer among laboratory workers. Lancet 1990;335:1097.

7. Carpenter L, Beral V, Roman E, Swerdlow AJ, Davies G. Cancer in laboratory workers. Lancet 1991;338:1080-1.

8. Hoar SK, Pell S. A retrospective cohort study of mortality and cancer incidence among chemists. J Occup Med 1981;7:48594.

9. Maher KV, Defonso LR. A historical cohort study of mortality among chemical researchers. Arch Environ Health 1986;41:109-6.

10. Belli S, Comba P, De Santis M, Grignoli M, Sasco AJ. Mortality study of workers employed by the Italian National Institute of Health, 1960-1989. Scand J Work Environ Health 
1992;18:64-7.

11. Walrath J, Li FP, Hoar SK, Mead MW, Frameni JF. Causes of death among female chemists. Am J Public Health 1985; 15:883-5

12. Dosemeci M, Alavbanja M, Vetter R, Eaton B, Blair A. Mortality among Laboratory Workers Employed at the United States Department of Agriculture. Epidemiology 1992;3:258-2.

13. Harris AL, Neal DE. Bladder cancer - field versus clonal origin. N Engl J Med 1992;326:759 - 761 .

14. Sidransky D, Frost $P$, von Eschenbach A, Oyasu R, Preisinger
A, Vogelstein B. Clonal origin of bladder cancer. N Engl J Med 1992;326:737-40.

15. Silverman DT, Hartge P, Morrison AS, Devesa SS. Epidemiology of bladder cancer. Hematol Oncol Clin North Am 1992;6:1-30

16. Axelson $\mathrm{O}$. Aspects on confounding in occupational health epidemiology [letter]. Scand J Work Environ Health 1978;4: $98-102$.

Received for publication: 31 December 1993 